\title{
REVIVAL OF FORGOTTEN RIVERS THROUGH RECREATING THE CULTURAL PROMENADE: A CASE STUDY OF THE REVIVAL OF BEIRUT RIVER, LEBANON
}

\author{
MAGED YOUSSEF \& BASHIR ABOU ALI \\ Faculty of Architecture, Design and Built Environment, Beirut Arab University, Lebanon
}

\begin{abstract}
The river is a natural stream of fresh water flowing into a channel to the sea, a lake, or another river. It is a productive resource and vital to its environment, agriculture, industry, energy, household, transportation, generation, culture and recreation. It plays a significant role in people's lives and a city's shape. Generally, rivers can be considered the center of the city's evolution, but nowadays river connection among cities, societies, cultures and the environment is unclear. One of the city's major problems, especially in third-world nations, is 'dead rivers' or 'forgotten rivers', which become sources of pollution and disease, forming a dead path, fragmenting communities, degrading biodiversity, with urban encroachment, the absence of a healthy environment and the loss of community aesthetic value. This paper envisions that negligence of rivers can be one of the most important causes for the death of a city, whereas the revival of rivers has become a must for cities targeting re-living and development. Therefore, this paper aims to propose an urban strategy, as a solution to revive the forgotten rivers, through creating a cultural promenade on its shore. Beirut River in Lebanon is a forgotten river that burdens Beirut city with a lack of any decent quality of life, a dead polluted space, a forgotten area fragmenting the city, which should be the main potential gathering space for nature, tourism and investments. As a case study, this paper investigates Beirut River through urban and ecological analyses, aiming to design an urban strategy for reviving it by creating a cultural promenade enriched with public spaces and green areas, which can most probably enhance the quality of life in the city. The paper ends with a set of conclusions, stating that focusing on a forgotten river and turning it into a sustainable basin may rehabilitate its city and reform its identity.
\end{abstract}

Keywords: architecture, forgotten river, promenade, revival, culture, landscape.

\section{INTRODUCTION}

Waterfronts are dynamic natural sites and environmental edges, reflecting the identities of cities, managing the balance between nature, culture and social life towards sustainable cities. The water body may be a lake, canal, river, ocean, bay or creek. A river is an important planning element which fulfills comfort for physical and psychological needs. According to the Turkish researcher of forestry, Umut Pekin Timur:

Cities seek a waterfront that is a place of public enjoyment. They want a waterfront where there is ample visual and physical public access, to both the water and the land. Cities also want a waterfront that serves more than one purpose: they want it to be a place to work and to live, as well as a place to play. In other words, they want a place that contributes to the quality of life in all of its aspects - economic, social, and cultural [1].

The importance of urban rivers has been recognized for water resources, fisheries and recreation in view of their contributions to landscape and protection of nature. Moreover, rivers have certain definite environmental, cultural, social and economic values [2].

They are used by humans on a variety of purposes such as water drinking, irrigation, fishing, swimming, industry, transportation, power production, flood control and aesthetic enjoyment. Rivers have a variety of functions in the city like providing connections between landscapes and communities and integrating people with a creative environment. Rivers are 
the basic central point of a cities' development and evolution. Many cities around the world are shaped linearly along a river path, such as the Thames in London, the Seine in Paris, the Danube in Budapest, and the Hudson in New York [3]. There is no doubt that a river gives life to city. Rivers penetrating cities are considered renewable arteries that generate power, energy and recreation to people. Unfortunately, many cities, particularly in the third world nations, have rivers that are totally neglected, mishandled and contaminated. The surrounding environments therefore became unhealthy in these areas. As shown in Fig. 1, rivers in these cities suffer from lack of integration between people and nature, between communities and local authorities, insufficient waste measure, absence of wastewater managements where sewage runoff over the river, absence of open and green public spaces, degraded biodiversity and loss of habitat, urban heat island effect, urban encroachment on the river, and water pollution causing odor nuisance and health risks [4].

All of the aforementioned problems have turned certain cities into graveyards, inhabited by people walking like ghosts, built by speechless, non-expressive and pale buildings. In cities such as; Cairo, Baghdad, and Beirut, the communities lost their aesthetics values, routine ruled people's behaviors, sources of inspiration have been disappeared, pollution became everywhere and cities started to die clinically. Negligence of rivers can be one of the most important reasons why certain cities died. Ignorance of governments and civil societies in finding solutions for these rivers caused a noticeable deterioration in life quality. Cultural and entertainment facilities are absent from these rivers, so the identity of the spine is lost. In these cases, the river became a pollution source with absence of green areas and natural spaces, creating abnormal air quality causing serious health problems [5]. The main aim of this research is to produce urban solutions to the mentioned problems by creating activities on the river's shores and postulating a strategy for designing a cultural promenade waterfront following the urban principles of waterfront areas. As a case study, the paper will analyze and survey the current situation of the Beirut forgotten river recognizing its main problems, and proposing to create a cultural promenade on its most vital spots attracting tourists and residents. This promenade is expected to be the city's new spine and a potential gathering space for multi-use investments. The research hypothesizes that creating a cultural promenade on a forgotten river's shores can revive this river giving a new image of the city and feeding people's lives with a positive energy.

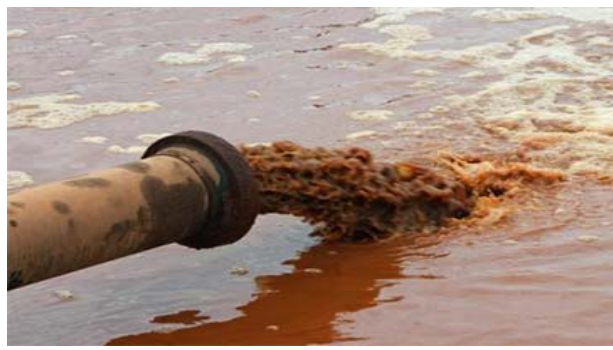

(a)

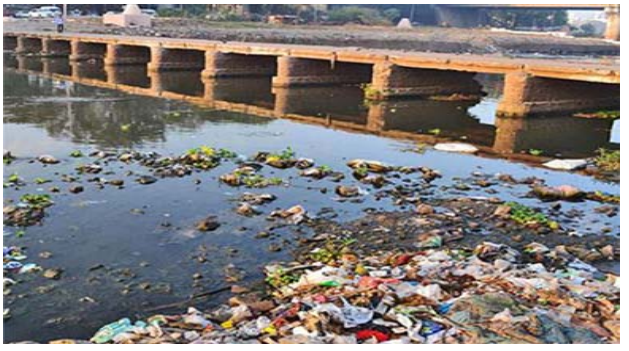

(b)

Figure 1: Examples of problems in rivers. (a) Industrial waste and sewage in Mississippi River, Brazil; (b) Wastes on Mula Mutha River, India. 


\section{LITERATURE REVIEW}

'Forgotten rivers' is a research subject that several critics and authors wrote about. In 1998, the urban planner Michael E. Landis published a book talking about the importance of waterfront areas and their reviving functions. Later on, in 2002, a British environmental agency published research entitled; 'River Restoration' clarifying visions of environmental sustainable global cities [6]. After that, in 2006, Doshik Yang made his PhD Thesis, entitled 'Waterfronts: Spatial Composition and Culture Use'. In 2009, the Lebanese architect Sandra Frem defended her master thesis in MIT, Massachusetts Institute of Technology, under the name, 'Nahr Beirut: Projections on an infrastructure landscape' [7]. In 2011, Joellen Anderson published a book about mobilizing rivers, whereas Aaron Hanson dealt in 2012 with forgotten rivers by reconnecting ecological solutions. In November 2015, the Lebanese critic Hammoud Badawi presented an idea of returning the forgotten rivers back to life by using Beirut River as a case study. The old trials of reviving rivers, as shown in Fig. 2, begun in 1930s, by restoring Rhine River in Germany through improving water's quality, relocation, fish inhabitation, and habitat variety improvements. Yangtze River in China was restored in 1954, and since then, the approach of environmental revival began spreading across the world. In 1999, fresh water was provided in Denmark by restoring Skiem River which is considered the biggest river revival in North Europe [8]. At the present time, reviving rivers has become wide spread. USA is one of the most countries that restored its forgotten rivers by reviving rivers of Missouri, Kissimmee, Chesapeake, Boston Bay, etc. Sustainable urban projects were done in Europe, restoring Mersey River in the United Kingdom, Rotterdam River in Netherlands, Prda River in Poland, and Tirana River in Albania. All recent studies and projects show the importance of reviving the forgotten rivers all around the world, especially in the countries that have lack of future planning [8]. What is meant by mentioning these works is to send a message to the governors of these cities which suffer from its forgotten rivers.

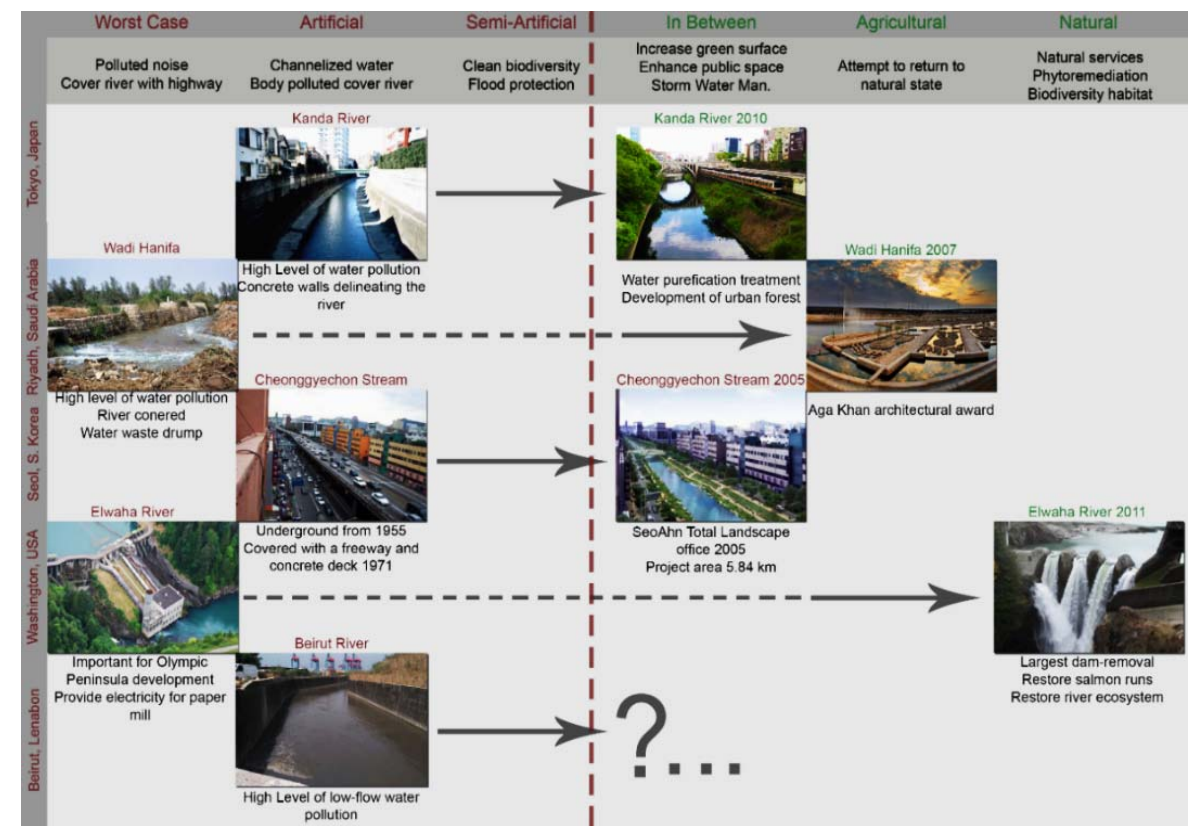

Figure 2: Successful similar examples showing effects of revival projects. 
The plan developed by the GLA, the Greater London Authority, and the Mayor of London, seeks to keep the River Thames as the most important and sustainable river in the world. This plan seeks to keep the river clean, functional, and sustainable. It presented a vision for London as an 'exemplary sustainable world city' [9]. Based on the previous studies and projects, it can be said that, the basic idea of riving a river is to fulfill an ecological equilibrium, increasing security, allowing anthropic activities, and reducing costs of management and intervention. As a focused case study, the paper selects 'the forgotten river of Beirut' be analyzed by a scientific methodology as follows.

\section{METHODOLOGY}

The paper uses various types of research methodology. These can be summarized as four types. First, the inductive method is used through gathering data around the chosen case study; 'Beirut River', recognizing its different changes along history. Second, the field method, the authors visited certain sites in 'Beirut River', taking live photographs, sketching, and undertaking interviews with a sample of people living near the river. Beside the interviews, a written questionnaire was distributed on this sample to recognize their point of views on the river's existing problems and the possible ways to develop it. Third, the analytical method, the paper analyzes results of interviews and the questionnaire. Finally, the deductive method, the paper deducts a strategy of certain solutions to revive the forgotten rivers by creating cultural activities on its banks. The four research methodologies are presented through the research as follows.

\subsection{Introducing the case study of 'The Beirut Forgotten River'}

Nowadays, Beirut, the capital of Lebanon, is suffering from an absence of green areas and public open spaces. The ratio of green space to a population of 1.6 million is shocking. Beirut city provides 0.4 square meters of green spaces for every person in which the standard level is more than 60 times this proportion [7]. Moreover, a huge area is lost by the presence of a dead element that passes in through the city, the Beirut River that reaches the Mediterranean Sea, as shown in Fig. 3.

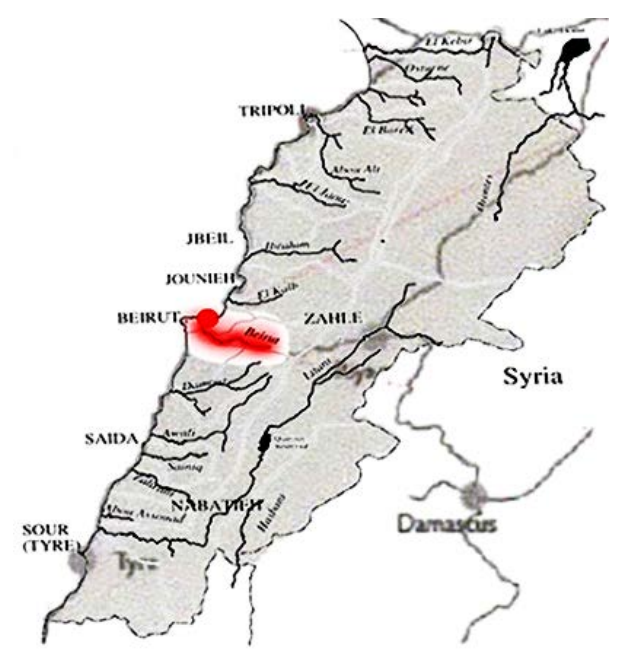

Figure 3: A map showing Beirut River and the other Lebanese rivers. (Source: Educational Geographic Encyclopedia in Lebanon, 2011.) 
Beirut River is one of the forgotten rivers around the world. As shown in Fig. 4, its length is $25 \mathrm{~km}$ starting from a mountain of $1580 \mathrm{~m}$ height before changing its direction to flow north in its last $5 \mathrm{~km}$ through Beirut Peninsula, to emptying finally in the Mediterranean Sea at Beirut North waterfront, east of Beirut Port. The flow of Beirut River varies according to different seasons, as shown in Fig. 5, and the precipitation ratio during winter influenced by rainfall and snowmelt, reaches 100 million cubic meter as total discharge, 100,000 cubic meters as annual eroded materials, approximate flow rate $16 \mathrm{~m}^{3} / \mathrm{sec}$ during wet season (November-April), while during dry season (May-October) the flow rate reaches $0.01 \mathrm{~m}^{3} / \mathrm{sec}$, in which the flood maximum flow rate (100 year flood) may reach $1571 \mathrm{~m}^{2} / \mathrm{sec}$ [10].

Beirut owes a favor to the American group who came in 1958 and made an engineering study to construct a canal determining the path for the river. This study aimed to prevent water flood from overrunning its limits. The need to execute this idea was to end 100 years of flood risk, changing its irregular form be trapped in a regular canal. The construction process took ten years to be done [11].

\subsection{Urban analysis of 'Beirut River'}

As a result of its urban and natural land uses, Beirut River comprises three main zones: the waterfront zone, the urban zone, and the agricultural transition zone. The following analyses will explain the flow of Beirut River in each zone.

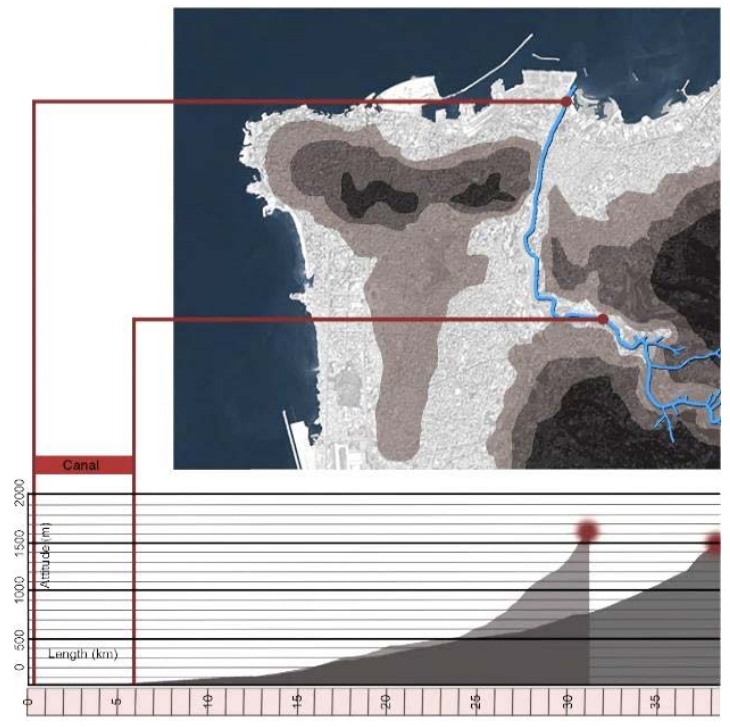

Figure 4: Beirut River path in Beirut and section shows its vertical flow from the source to its estuary. (Source: Lebanese Army geological data 2015.)

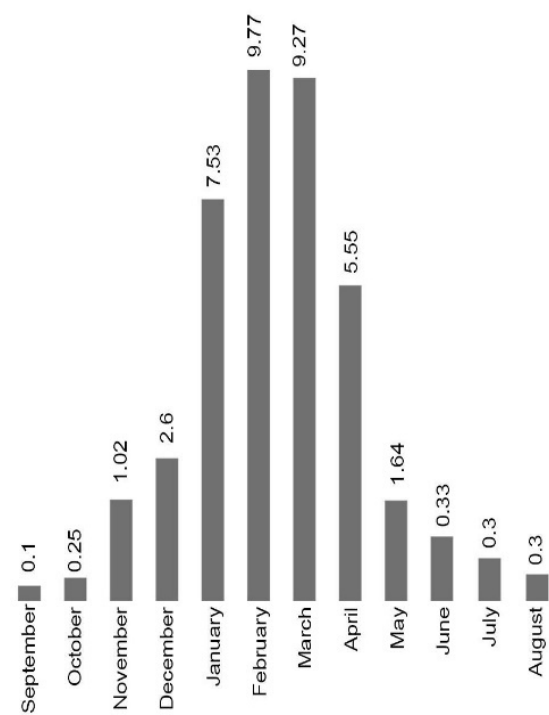

Figure 5: Beirut River hydrological statistics within different months. (Source: Pierre Gerard, 2001 [10].) 


\subsubsection{First zone: The Waterfront Zone}

The waterfront zone comprises a predominant industrial land use, as shown in Fig. 6. The public domain line is clearly defined by the property walls which separate the existing factories from the water. The existing waterfront is occupied by a 30-year-old landfill, an old fishermen port, a beach and estuary, which are polluted by the industrial outfall canals, a waste treatment plant and the port's markets [11]. The slaughterhouse is located at the intersection of the port and the industrial zone located at its back. The channel's profile in this section is 43 meters wide and slowly narrows towards the tip with an average height of 3 meters. It extends over the first 2.4 kilometers with a $1.5 \%$ slope 2 . The maximum water velocity for this section is 5.7 (for an 1100 cubic meters/second flood) [10].

\subsubsection{Second zone: The Urban Zone}

As shown in Fig. 7, the urban zone comprises dense residential neighborhoods on Bourj Hammoud and Sin El Fil side, and an institutional strip on the Beirut side, behind which are located the residential neighborhoods of Achrafieh. The channel in this section is sandwiched between the regional highway on Beirut's side, and a local road on the opposite bank. This zone suffers from lack of green areas and open spaces. Its profile is 35 meters wide by 5 meters high, and extends on $1.65 \mathrm{~km}$ with $3.5 \%$ slope [7].
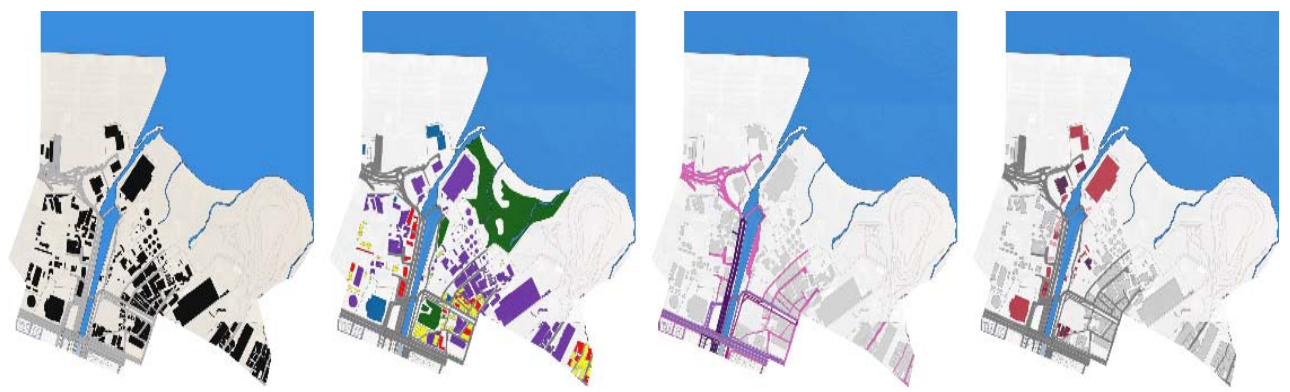

Figure 6: Waterfront zone urban analysis: empty/built area, land use, street and road network and building heights.

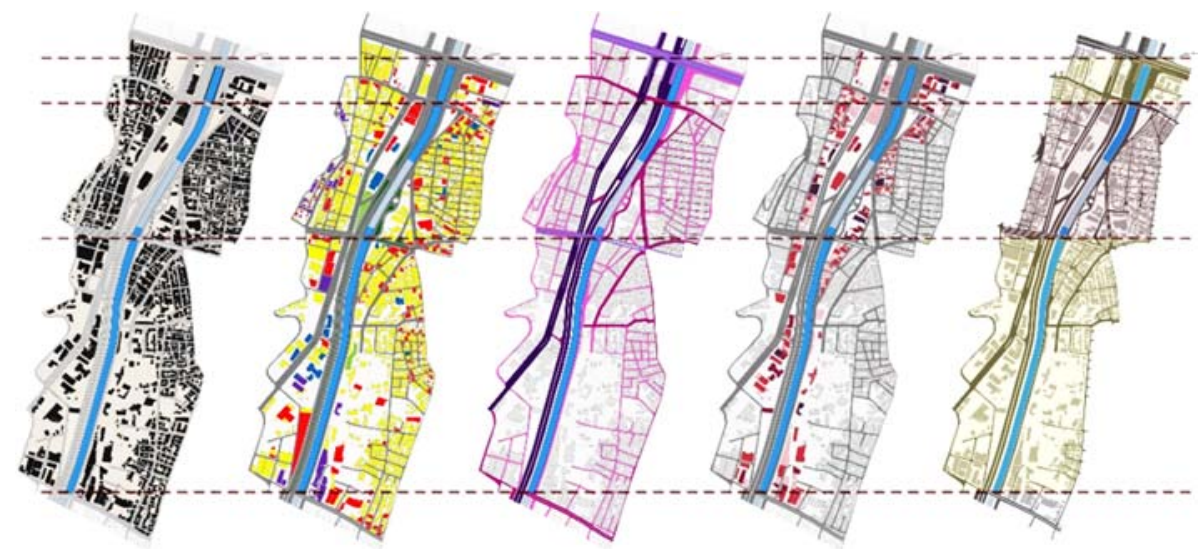

Figure 7: Urban zone urban analysis: empty/built area, land use, street and road network and building heights by specifying the densest area in this zone. 

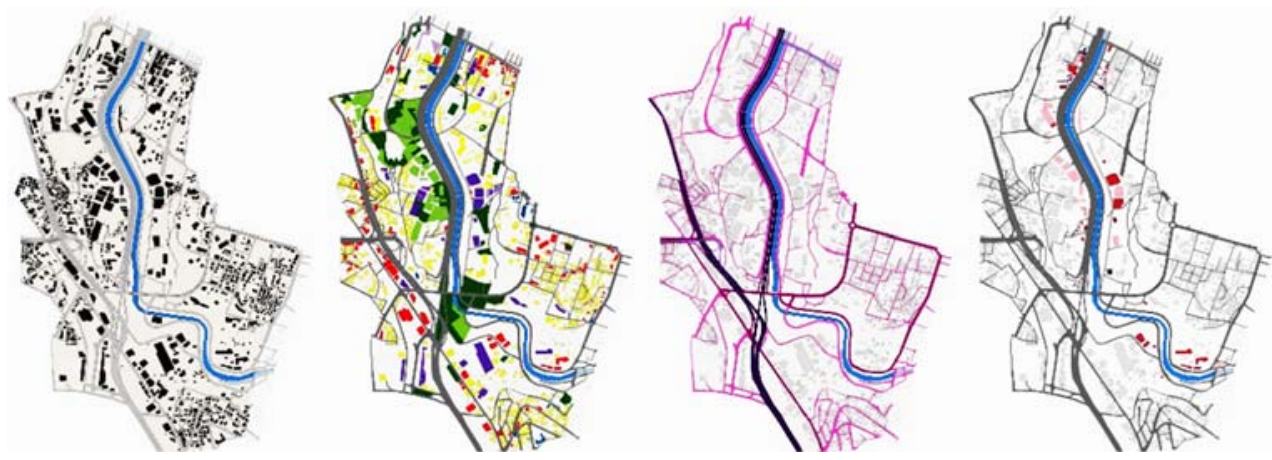

Figure 8: Agricultural transition zone urban analysis: empty/built area, land use, street and road network and building heights.

\subsubsection{Third zone: Agricultural Transition Zone}

This section is mostly open space comprising agricultural fields which is represented with railway stations, the last substantial open space in Beirut. The channel in this section becomes narrower and the walls higher, with a width of 23 meters, a height of 7 meters, and a slope of $6.5 \%$. Starting this section, the channel is flanked on both banks by strips of vegetation, buffering the adjacent roads and extends this way until the end of the channel in the valley section, shown in Fig. 8 [7], [10].

\subsection{Identifying problems of 'Beirut River'}

Unfortunately, Beirut River plays a role in fragmenting Beirut city due to the absence of any ecosystem along the strip. Moreover, the quantity of water during late summer and before winter is actually null, with a high pollution ratio from different sources with dead and forgotten spaces without any care of the river or its surrounding shores. "Beirut" is a Phoenician word meaning well or wells. That means that the city was rich in water and pure water from a very ancient time, particularly from the time the Roman Empire. Citizens and tourists can see the Roman ruins in the city center (Downtown) and on the river's banks obviously [7], [10].

Beirut River passes through different municipalities relating to central Beirut and to its suburbs. By analyzing the evolution map of Beirut development, it can be observed the bad care of the river, and the neglecting way of dealing with its natural path, especially that this river after its canalization plays a role in fragmenting the city. Unexpectedly, the river path has differentiated between its two opposite shores. Clearly, the identity of people, buildings, and investments became differentiated from a shore to another which caused an absence of communication and integration among people. Geography of Lebanon gives it a special place different from its surrounding in the Middle East, but these spaces instead of being positive and added value to Lebanese cities, are source of cities death, preventing interaction between communities and sources of pollution of city. In fact, Beirut River is suffering from several problems threatening the future of Beirut, especially the climatic problems that are pervading Earth day after day. Along the river, there is insufficient waste management, absence of wastewater management, sewage and storm water runoff into the river, with absence of open and green spaces causing the urban heat island effect. In addition to the absence of public transportation, the people miss pedestrian-walkways along the river's banks. Other negative 
phenomena such as; urban encroachment, high buildings, and population density along the river, with an absence of social, cultural and entertainment facilities lead to a blockage of interaction among people, community and local authorities. Other dangers and health risks are raised due to the spread of diseases, odor nuisance, and the existence of wild animals as crocodiles, as shown in Fig. 9.

All of the problems are found in this canalized polluted path, fragmenting Beirut into two spaces. Revival of these dead or forgotten areas became a must to prevent cities from future poison as diseases that affect their lives and health. This development may be the first strong revival for a city on economic, social, culture and touristic levels [10].

\subsection{Selection of a specific area in 'Beirut River'}

To concentrate the study, the research selects a specific area of the river, shown in Fig.10. It is located in the densest site in the second zone, 'The Urban Zone' that suffers from absence of green areas, open spaces and any cultural, social and entertainment facilities. Moreover, this completes the cultural map of Beirut cultural sites, as shown in the map of Fig. 11.
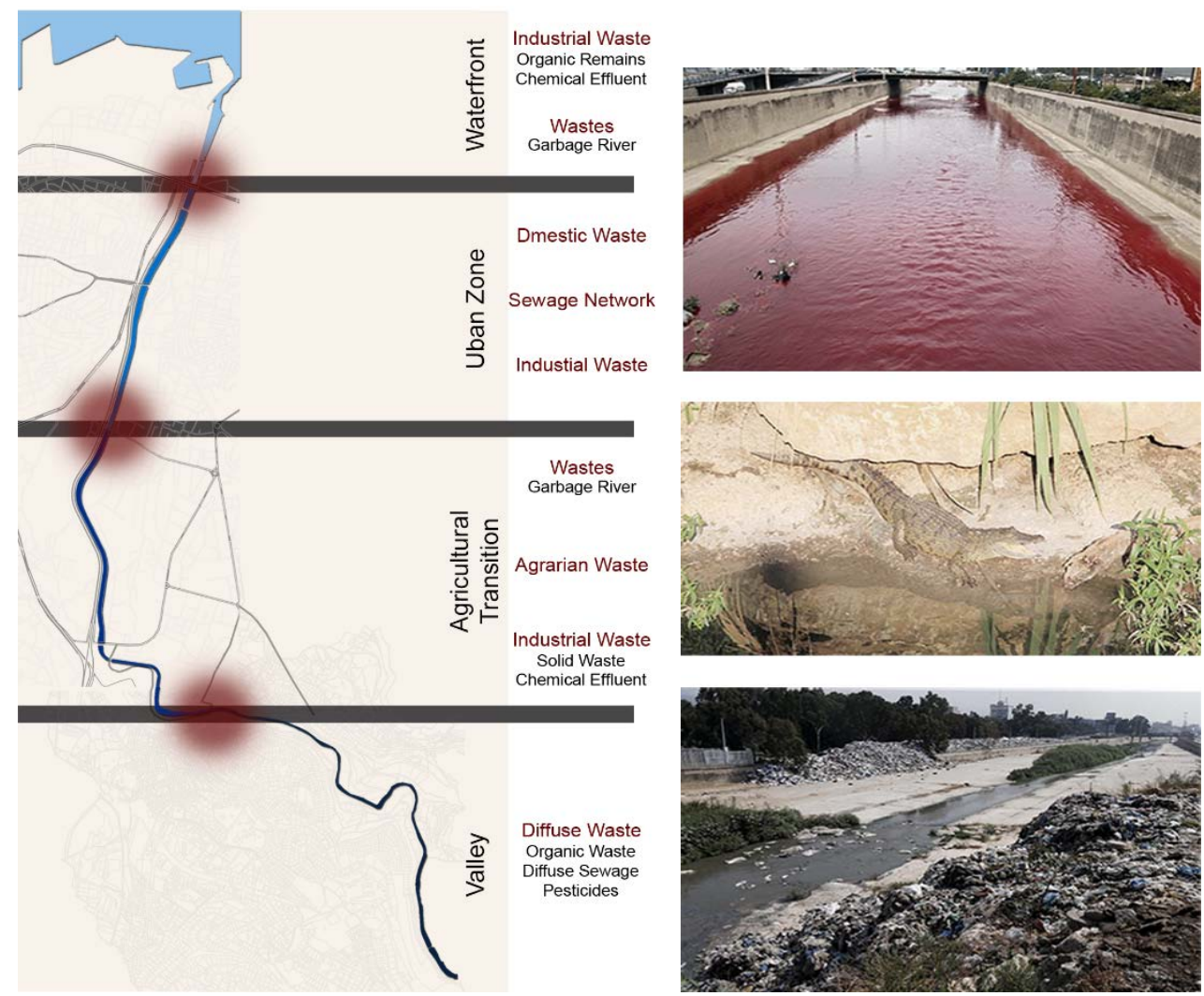

Figure 9: Pollution sources along Beirut River according to different zones. (Source: The Daily Star, Beirut Municipality, photo-credit to the authors, Nov. 2016.) 


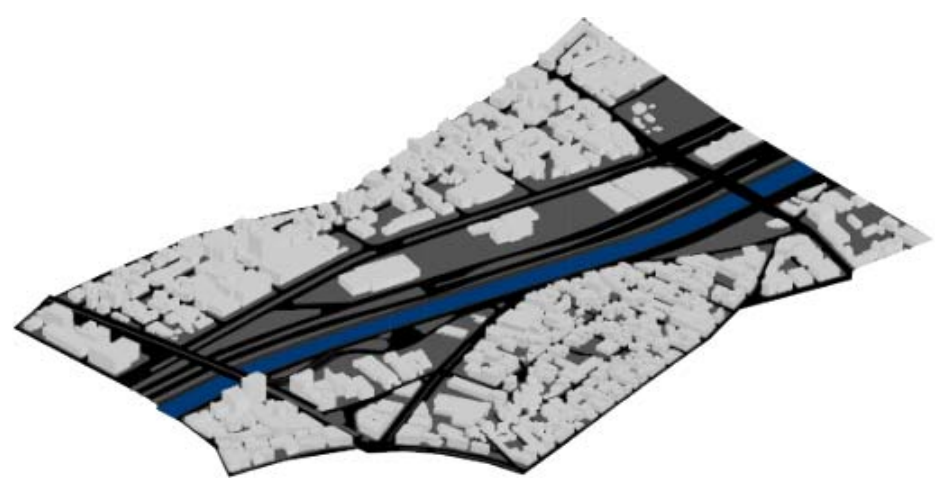

Figure 10: The selected area.

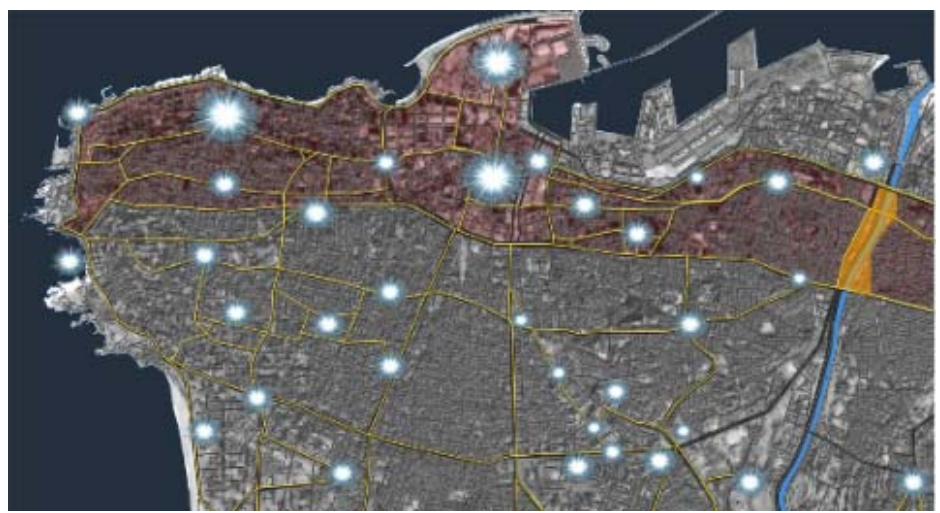

Figure 11: Cultural zones in Beirut city.

\subsection{Different perspectives of public on 'Beirut River'}

Seeking credibility and more interaction with people, this research preferred to meet a sample of the public who live and work in the selected area of Beirut River. To recognize the sample's point of view, visions, needs, and memories, the research followed two simple field methods; holding interviews and distributing a questionnaire form as follows.

\subsubsection{Holding Interviews}

Face to face interviews were made, from 25 to 30 November 2016, with ten elderly people that lived their life near Beirut River, and they represented a lot of interesting memories with the space. During interviews, three questions were asked:

a. How do you consider yourself belonging to Beirut River?

b. What do you remember from old memories in Beirut River (cultural, social, life style, promenade, shore)?

c. How do you consider the level of its existing situation compared to old period?

Answers were mostly similar; samples of these answers can be presented through the following quotations: 
Avedis Hovhannessian, 82 years old:

Belongingness to the river is spiritual, cultural and involuntary from the time of opening our eyes. As all the other children, we used to play with water. The sand of the river was very soft, we used to play with it, and our parents used it for construction. The water was fresh, different types of fish in it. My father had a small boat and we used to go fishing. Days and Years passed by, we grew old and so did the city. The river is not what it used to be 70 years ago... everything has changed ever since.

Antoine Dagher, 78 years old:

I remember nature was all around the river all sorts of plants, trees, fruits, flowers. It was beautiful, banana and lemon trees, and tomatoes. Like everyone else, we used to play in the river taking our bath there, our mothers used to clean clothes. We used to even drink the water from the river irrigate the lands. Things had already gotten worse before the Civil War but at least it was better than dead situation nowadays.

Sarkis Sarkissian, 73 years old:

Beirut River is my life, my rare jewelry that I own alone, due to what I lived before not to what I'm living now. We used to play, catch snake fish, frogs in the river. My mother used to get water for cooking. Our lives were based around the river, tramway passed over the bridge. There was a low bridge connecting the two shores, it was a beautiful bridge with a Victorian balustrade. They used to talk about an old roman bridge that used to exist in its place, but I cannot remember it. I hope that I died with my old memories of rivers life, and I do not see it in this situation.

Two of interviewed people cried while talking about the difference between the lived period of the river and the existing bad situation.

\subsubsection{Questionnaire}

A closed questionnaire was designed and distributed on 120 educated people of engineers, architects, judges, doctors, politicians, and business men, in the age group between 25 and 50 years old. This questionnaire was submitted equally in the three different zones of Beirut River, each alone in order to gain results on each sector. Questions mentioned in this form were directed, simple, and specific as follows:

a. What is your opinion in the existing Beirut River?

b. What is your vision on shores' function?

c. What is your vision on river activities?

d. What is your vision on transportation types along the promenade?

After achieving the field methodology, the paper analyzes results and findings of answers.

\section{FINDINGS}

Through using an analytical methodology, results of answers can be presented in form of sketches and charts.

\subsection{Analysis of interviews results}

Answers of interviews were given to two young Lebanese architects. Each one reformulated answers through visionary sketches according to his feelings and creativity. 

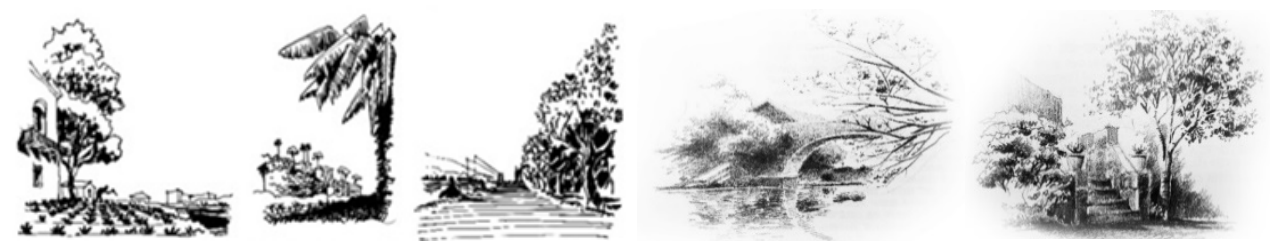

Figure 12: Sketches of the Lebanese architects Mohammad Tohme and Liwaa Amer.

As shown in Fig. 12, sketches of the two architects envision reviving Beirut River through adding landscape elements, a cultural promenade, and a clear surface of water. These sketches re-give the river its spiritual and romantic dimensions as the old days.

\subsection{Analysis of questionnaire results}

Results are formulated through statistical charts that are based on specific cultural, social background, and economic level. Charts shown in Figs 13 and 14 represents the results.

\section{DISCUSSION}

The previous findings emphasized the importance of creating cultural activities on the river's shores, which may draw a distinctive image for the city. The reviving process may consist of hydrological and ecosystem infrastructures in addition to solving pollutants and community treatment. The most important element of this process is the cultural promenade which can support social interaction, economy development, and providing open spaces for dense communities [13]. As an urban strategy for sustainable development and planning reviving rivers, this paper proposes applying the following solutions.

a. Constructing a continuous path along the river, for pedestrians and sustainable transportation as bicycles, electrical train, river ships, as shown in Fig. 15.

b. Creating a new vision of water/lands relation by providing empty lots and changing street-network to guarantee continuity for the intended promenade.

c. Along the promenade, a screen of stone arcades can be constructed to emphasize the city's architectural style. This screen can be decorated with wooden elements, 'arabesque', and stained glass.
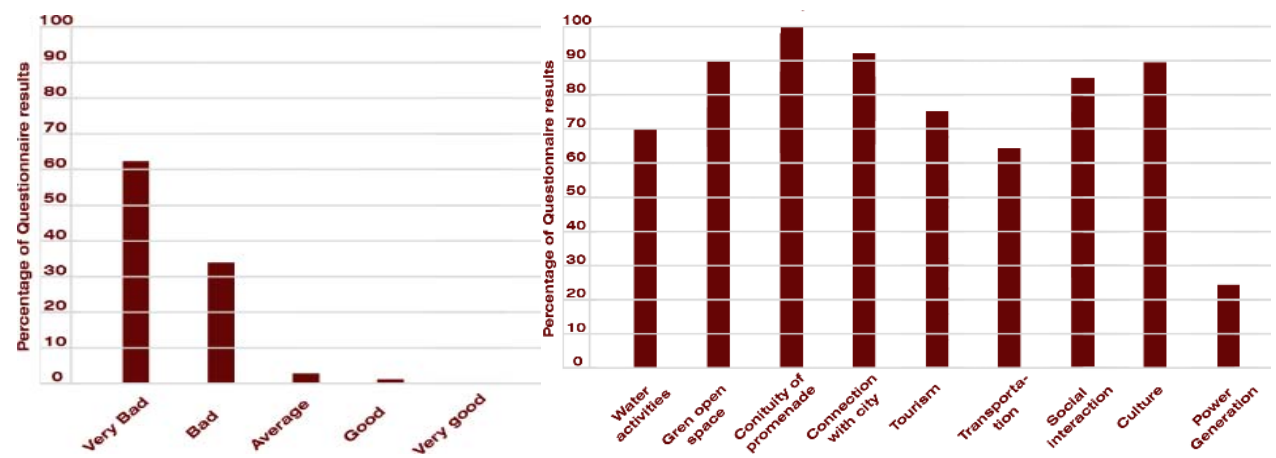

Figure 13: (a) On the left: most opinions of the existing river were "It is very bad"; (b) On the right: most of visions on shore function requested to continue shores as a promenade. 

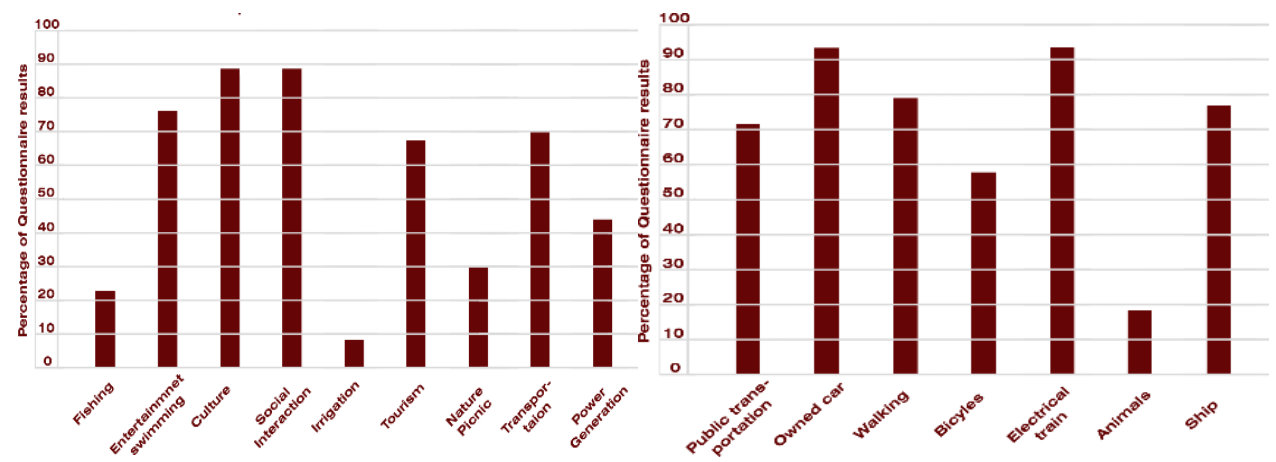

Figure 14: (a) On the left: most of visions on river activities requested to create cultural and social activities on the shores; (b) On the right: answers preferred that the owned cars and an electrical train become transportation types along the promenade.
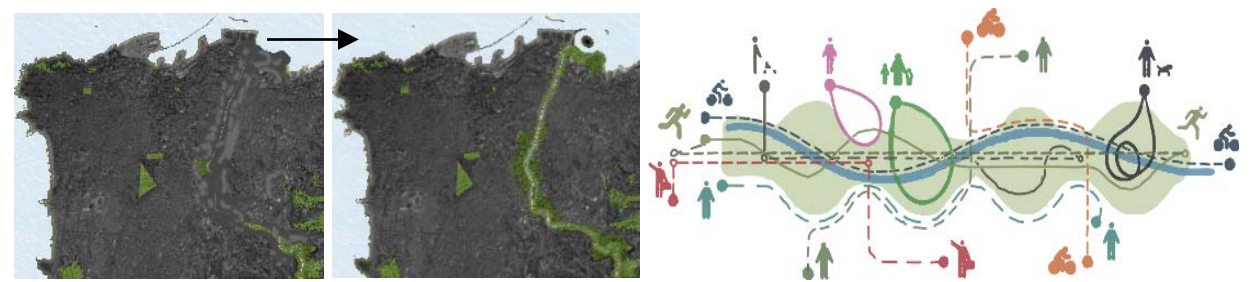

Figure 15: Green spaces provided to Beirut city and sketch shows envisions on promenade providing several activities.

d. Cultural and entertainment elements can be added on certain spots of the promenade such as; an amphitheater narrating the local history displaying folk shows or 'sound and light shows'. A remarkable wheel or cable-car transportation can offer thrill and amusement to public and tourists.

e. Landscape elements can be implanted to provide clean, healthy, and green environment for users of the promenade.

These solutions can be executed in reality through making a contact with the Lebanese Government which can hold an international competition for the best design proposal for this promenade. The government may order three bodies; Ministry of Tourism, Ministry of Environment, and Ministry of Public Works to contribute in initiating this project.

\section{CONCLUSION}

Finally, this paper ends with a set of a group of conclusions as follows:

a) The river should represent an iconic symbol of community heritage and its riverfront demonstrates a great potential for becoming a central axis in a new and green space.

b) For future plans, the concept of reviving rivers must be based of three essential steps:

- Empty lots: Taking benefits from empty lots along the river

- Continuity: Along the river by a promenade of a natural path, and across the river by pedestrian bridges connecting important sites. 
- Connectivity with the city: by connecting with important buildings along the shores with the promenade and inventing new buildings according to community needs and city's development planning.

c) The cultural promenade is a story-telling trip reflecting social, economic, touristic levels and history of the city by passing through continues sustainable green path along the river and connecting different facilities, buildings, and spaces to rebuild the visual image and identity of the city.

\section{REFERENCES}

[1] Timur, U.P., Urban Waterfront Regenerations, Department of Landscape Architecture, Faculty of Forestry, Çankiri Karatekin University: Çankiri, Turkey, 2012.

[2] Özyavuz, M., Advances in Landscape Architecture, 2013, Online. InTech CC BY 3.0., www.intechopen.com/books/advances-in-landscape-architecture. Accessed on: 11 Dec. 2016.

[3] Yang, D., Waterfronts, Spatial Composition, and Cultural Use, The Bartlett School of Architecture and Planning, University College London: London, England, pp. 17-20, 2006.

[4] Chen, C., A Study on Sustainable Riverfront Landscape Design, University of Florida: USA, pp. 12-14, 2011.

[5] Hanson, A., Reconnecting to a Forgotten River an ecological solution, Department of Landscape and Architecture of North Dakota State: USA, pp. 19, 2012.

[6] Miller, J., River Restoration: A stepping stone to urban regeneration highlighting the opportunities in South London, Environment Agency and Mayor of London, 2003, Online. www.gov.uk/government/organisations/environment-agency. Accessed on: 11 Nov. 2016.

[7] Frem, S., Nahr Beirut: Projections on an Infrastructure Landscape, Massachusetts Institute of Technology, Massachusetts: USA, pp. 15-41, 2009.

[8] Darby, S. \& Sear, D., River Restoration: Managing the Uncertainty in Restoring Physical Habitat, 1, Wiley: London, England, 2008.

[9] River Thames was compiled by Adrian Evans in 2011 Rivers of the World is a Thames Festival project delivered in partnership with the British Council's Connecting Classrooms with support from HSBC Global Education Program, Online. www.riversoftheworld.org. Accessed on: 25 Oct. 2016.

[10] Gerard, P.C., Les Transformations de I'Hydro-Systeme Fluvial de la Partie Aval du Nahr Beyrouth, Department of Geography, Saint-Joseph University: Beirut, Lebanon, 2001.

[11] Enjoy, talk, do, be, A Cultural Strategy for Torbay and its communities 2014-2024. Commissioned by TDA, funded by Arts Council England, 2014, Online. http://www.torbayculture.org/wp-content/uploads/2015/09/Enjoy-talk-do-beStrategy-document.pdf. Accessed on: 7 Nov. 2016. 